\title{
OS CONTEÚDOS DE EDUCAÇÃO FÍSICA: UMA ANÁLISE DOS RELATÓRIOS DE ESTÁGIO SUPERVISIONADO
}

\author{
Aline Rodrigues Guedes da Silva \\ Prefeitura Municipal de Corumbá. Brasil \\ nortonaline@hotmail.com · https://orcid.org/0000-0003-2429-1781 \\ Vivian Mendes de Souza \\ Universidade Federal da Grande Dourados - UFGD. Brasil \\ vivian_mendes09@hotmail.com·https://orcid.org/0000-0003-2904-0455 \\ Gustavo Levandoski \\ Universidade Federal da Grande Dourados - UFGD. Brasil \\ glevandoski@gmail.com ·https://orcid.org/0000-0002-2927-3868
}

\begin{abstract}
Resumo: Este estudo teve como objetivo analisar a frequência dos conteúdos de Educação Física nos relatórios de Estágio Supervisionado. A pesquisa é caracterizada como documental e exploratória, de caráter quali-quantitativo, realizada com 66 relatórios de Estágio do Ensino Fundamental e Ensino Médio de acadêmicos concluintes no ano de 2016 de uma Universidade Federal. O conteúdo mais desenvolvido no estágio das séries iniciais do Ensino Fundamental consistiu em atividades recreativas (32,3\%), já no estágio das séries finais do Ensino Fundamental e no Ensino Médio, foi a modalidade esportiva de voleibol (22\% e 38\% respectivamente). Concluímos que os acadêmicos se mostraram criativos ao desenvolver os planejamentos das aulas, considerando as dificuldades em encontrar nas escolas públicas materiais específicos e local apropriado para a prática esportiva.
\end{abstract}

Palavras-chave: Educação Física, estágio curricular supervisionado, formação de profesores, sporte.

\section{THE CONTENT OF PHYSICAL EDUCATION: AN ANALYSIS OF SUPERVISED PRACTICES REPORTS}

\begin{abstract}
The objective of this study was to analyze the frequency of Physical Education content in the Supervised Practice reports. This research has a documentary and exploratory nature, and was carried out through a qualitative and quantitative approach, analyzing 66 reports of Practice in Fundamental Teaching and Secondary Education, prepared by academics who graduated in 2016 from a Federal University. The content that was most developed in the Practice of the first years of the Fundamental Teaching were recreational activities (32.3\%); in the stage that covers the last years of the Fundamental Education and of the Secondary Education, the first place was occupied by the volleyball sports modality ( $22 \%$ and $38 \%$, respectively). It is concluded that the academics demonstrated creativity to plan the classes, given the difficulty to find specific materials in public schools, as well as an appropriate place to perform such sports practice.
\end{abstract}

Keywords: Physical Education, supervised curricular practice. teacher education, sport.

\section{EL CONTENIDO DE EDUCACIÓN FÍSICA: UN ANÁLISIS DE LOS INFORMES DE PRÁCTICAS SUPERVISADAS}


Resumen: En este estudio se propuso analizar la frecuencia del contenido de Educación Física en los informes de la Práctica Supervisada. Esta investigación tiene un carácter documental y exploratorio, y se realizó por medio de un enfoque cualitativo y cuantitativo, analizando 66 informes de Práctica en la Enseñanza Fundamental y Enseñanza Media, elaborados por académicos que se graduaron en 2016 de una Universidad Federal. El contenido que más se desarrolló en la Práctica de los primeros años de la Enseñanza Fundamental fueron las actividades recreativas (32,3\%); en la etapa que abarca los últimos años de la Enseñanza Fundamental y de la Enseñanza Media, el primer puesto lo ocupó la modalidad deportiva de voleibol (22\% y $38 \%$, respectivamente). Se concluye que los académicos demostraron creatividad para planificar las clases, dada la dificultad para encontrar materiales específicos en las escuelas públicas, así como un lugar apropiado para realizar tal práctica deportiva.

Palabras clave: Educación Física, práctica curricular supervisada, formación de profesores, deporte.

\section{Introdução}

A Educação Física, como componente curricular obrigatório na Educação Básica, possui uma diversidade de possibilidades temáticas a serem desenvolvidas na escola, tais como brincadeiras e jogos, esporte, dança, ginástica, lutas e práticas corporais de aventura, enfatizadas atualmente na Base Curricular Comum Nacional (BRASIL, 2018).

Ao longo deste estudo, será evidenciado que muitos conteúdos descritos como obrigatórios nas atividades curriculares de ensino não são desenvolvidas pelo corpo docente, corroborando com uma hipótese empírica de que os professores são reféns da inexistência de recursos didáticos e infraestrutura, o que afeta diretamente a qualidade do ensino.

Partindo desse pressuposto, buscou-se conhecer como é desenvolvido o Estágio Curricular de Educação Física de uma Universidade Federal, verificando se conteúdos como esporte e lazer são utilizados no ensino de Educação Física de escolas públicas.

Entendemos que a Educação Física tenha que oferecer possibilidades em que os alunos possam usufruir do lazer de maneira saudável. Pensando no esporte como uma prática de lazer, conforme proposto por Bracht (2005), que indica suas duas formas de prática (lazer e rendimento), a Educação Física Escolar necessita tratar dessa temática.

Além da possibilidade do esporte no lazer, a aula de Educação Física pode promover uma educação para o lazer, com o objetivo de conscientizar os cidadãos sobre a importância da efetivação de políticas públicas compreendendo o lazer como instrumento e como objeto de educação, com vistas à melhoria da qualidade de vida das pessoas (Chemin, 2009).

O conhecimento da amplitude dos conteúdos a serem tratados na Educação Física Escolar deve ser discutido na formação inicial, para que os acadêmicos tenham base teórica para reestruturar o estágio, seu primeiro contato com o campo de atuação. Para Luiz, Angeloni, De Maria, Maltez e Batinga (1995), o estágio serve como elemento da formação profissional, fazendo com que os acadêmicos adquiram em conjunto uma consciência crítica da análise de diferentes abordagens pedagógicas, aprofundem e construam sua identidade profissional de atuação na escola. Desse modo, o estágio permite ao acadêmico aplicar todo o conhecimento adquirido ao longo de sua formação, unindo a teoria e a prática.

Assim, é importante que os professores de Educação Física se estimulem para abordar um amplo leque de conteúdos no processo de ensino-aprendizagem, 
possibilitando que seus alunos vivenciem novas experiências educacionais. Para Hildebrandt (2003), a metodologia utilizada pode ser a maior responsável pelo aprimoramento das capacidades motoras, pela promoção da saúde, pelo desenvolvimento da personalidade da criança e do organismo, contribuindo também no desenvolvimento do sistema cardiovascular, do sistema nervoso e no aperfeiçoamento das qualidades físicas fundamentais.

A Educação Física na Educação Infantil tem um papel fundamental na vida das crianças, segundo Ayoub (2001), ela contribui com a linguagem corporal nos movimentos realizados, com a descoberta do corpo e de suas capacidades, como também na alfabetização. As atividades ginásticas podem ser grandes aliadas nessa etapa, pois, a partir de movimentos básicos, como correr, saltar, lançar e arremessar, sistematizamos o ensino dos demais conteúdos. Nessa fase, o objetivo seria estimular as crianças a realizar tais habilidades básicas por meio da ludicidade, com jogos e brincadeiras, para aperfeiçoar essas habilidades no Ensino Fundamental. De acordo com Oliveira (2006):

A grande tarefa e transformação didática e pedagógica dentro das escolas brasileiras é aumentar sua atratividade e sua compreensão, porque fazer, como fazer, quando fazer e como melhorar esse fazer, com diferentes estímulos e diferentes formas de adquirir o conhecimento (Oliveira, 2006, p. 28).

No Ensino Fundamental, os objetivos são aprimorar as habilidades básicas e a coordenação motora e ampliar o conhecimento sobre os demais conteúdos, como esporte, luta, dança. Mas, é preciso que a ludicidade prevaleça e que o professor de Educação Física utilize os jogos como instrumento pedagógico.

Os jogos podem influenciar significativamente na construção do conhecimento sendo uma fonte de prazer e descoberta. É preciso ver o jogo como uma atividade que faz parte do cotidiano do aluno, sendo um elo com a aprendizagem, pois o jogo é uma atividade espontânea do ser humano, a proposta de jogar para aprender e não aprender para jogar compreende objetivo e não repetir fundamentos específicos deles (Oliveira, 2006, p. 38). (1999):

No Ensino Médio, a Educação Física segundo Darido, Galvão, Ferreira e Fiorin

deve proporcionar ao aluno conhecimento sobre a cultura corporal de movimento, que implicam compreensão, reflexão, análise crítica, etc. A aquisição de tal corpo de conhecimentos deverá ocorrer em relação às vivências das atividades corporais com objetivos vinculados ao lazer, saúde/bem-estar e expressão de sentimentos. Este objetivo precisa ser garantido a todos os alunos, pois permitirá uma plena autonomia no usufruto das formas culturais do movimento. (p. 140).

Nessa etapa educacional, os alunos se questionam muito sobre a importância da Educação Física e principalmente o porquê de fazer essa aula. Por esse motivo, é fundamental que o professor de Educação Física desperte no aluno o interesse por refletir sobre a cultura corporal do movimento e por compreendê-la, como citam Darido et al. (1999).

Segundo Bassani, Torri e Vaz (2005), um dos desafios no ensino da Educação Física é conseguir a unanimidade por parte de crianças e adolescentes na prática das atividades físicas durante as aulas. Os autores observam que muitos estudantes vão para 
as aulas de Educação Física, porém não realizam as atividades práticas propostas pelo professor, o que sugere que eles estariam satisfeitos apenas por quebrar suas rotinas ao saírem da sala de aula.

Diante desse contexto, o professor de Educação Física pode criar uma metodologia diversificada, utilizando vídeos, textos para discussões, temas atuais dentro do esporte, além de elaborar uma aula dinâmica que atenda seu público na sala de aula. O professor pode trabalhar diferentes temas, como história, doping, anatomia do corpo, análise do movimento, esporte nas Olimpíadas, benefícios do esporte e também cuidados para não prejudicar a saúde, entre outros. Para o adolescente participar e principalmente se interessar pelo conteúdo, muito depende de como o ensino é abordado na sala de aula, por isso devemos sempre buscar novos métodos, novas ideias e possibilidades de ensino.

Também se propõe um aprofundamento das dimensões que podem ampliar o conhecimento do aluno nas aulas de Educação Física. Segundo Maldonado, Bocchini, Barreto e Rodrigues (2014), o professor necessita pensar nos conceitos de determinado conteúdo (dimensão conceitual), em seus fundamentos e suas técnicas (dimensão procedimental) e também nos valores e nas atitudes que esse conteúdo desperta nos alunos (dimensão atitudinal). Dessa forma, poderá realizar um bom planejamento e oferecer uma gama de conteúdos condizente com o contexto atual da Educação Física.

Além disso, Netto e Pimentel (2009) afirmam que, além da falta de material e infraestrutura, os professores necessitam buscar conhecimentos sobre metodologias e práticas para uma atualização em seu trabalho. Pereira e Moreira (2005) afirmam, ao avaliar alunos que estudam no Ensino Médio, que a intervenção dos professores quanto à ausência nas aulas ou à desistência por parte dos alunos é quase nula, indicando que existe uma forte relação entre a conduta do professor, a proposta de conteúdos, a participação e a expectativa dos alunos quanto à aula.

Todas essas questões são levantadas na formação inicial em Educação Física. A observação dessa realidade e o planejamento de uma intervenção são estudados no Estágio Curricular Supervisionado, que é regulamentado pela Lei $\mathrm{n}^{\mathrm{o}} 11.788$ de 25/09/2008 (Brasil, 2008). Esse instrumento legal determina que o estágio deve ocorrer em instituições que permitam seu desenvolvimento em condições adequadas, proporcionando melhor formação. Ele deve ser planejado, executado, acompanhado e avaliado, sendo realizado na Educação Infantil, no Ensino Fundamental e no Ensino Médio.

Conforme o Manual de Orientação do estágio supervisionado do curso participante deste estudo, o estágio deve iniciar na etapa final do curso, a partir do $6^{\circ}$ semestre até o $8^{\circ}$ semestre, de modo que o estudante:

em busca de uma melhor formação profissional, já esteja com uma base teórica que sustente sua prática de estagiário. Sendo assim, o Estágio deve ter vínculo curricular, deve ser orientado e supervisionado por um professor licenciado em Educação Física, sendo obrigatório o seu cumprimento para a certificação conclusiva da formação do aluno (UFGD, 2016, p. 2).

Dessa forma, os objetivos da disciplina de Estágio são:

I - Conhecer a realidade educacional na qual se insere o campo de atuação profissional do futuro professor. 
II - Oportunizar situações para que o acadêmico possa relacionar a teoria à prática educacional, no atual contexto sócio-político-econômico.

III - Proporcionar momentos para uma reflexão contextualizada por meio da vivência institucional, sistemática, intencional.

IV - Oportunizar situações para o acadêmico demonstrar iniciativa, decisão e criatividade.

V - Permitir ao acadêmico manifestar seu senso crítico, avaliando a realidade educacional, o curso de Licenciatura em Educação Física e o seu futuro desempenho profissional.

VI - Diagnosticar, executar e avaliar as atividades pedagógicas na Educação Infantil, no Ensino Fundamental e no Ensino Médio.

VII - Refletir sobre a prática à luz das teorias estudadas, propiciando o referencial teórico-prático necessário para que o futuro professor desenvolva uma postura crítica sobre a educação (UFGD, 2016, p. 3).

De acordo com o Projeto Pedagógico do Curso (PPC) de Licenciatura em Educação Física da instituição pesquisada, a carga horária exigida para o estágio é de 504 horas, dividida em todas as etapas da Educação Básica. A matriz curricular dispõe de três disciplinas: Estágio Supervisionado e Prática de Ensino de Educação Física na Educação Infantil e nos anos Iniciais do Ensino Fundamental (180 horas); Estágio Supervisionado e Prática de Ensino de Educação Física nos anos Finais do Ensino Fundamental (180 horas); e Estágio Supervisionado e Prática de Ensino de Educação Física no Ensino Médio (144 horas).

Em cada estágio, o acadêmico deve acompanhar e observar o professor regente de Educação Física da escola para, logo após, aplicar sua regência. Ao acompanhar o professor de Educação Física, o acadêmico registra o conteúdo ministrado, a quantidade de aulas e alunos, os materiais utilizados, o objetivo da aula, as atividades propostas, entre outras informações. Na regência, o acadêmico é quem toma a posição de professor, ministrando as aulas de Educação Física. Além disso, o acadêmico deve fazer planos de aula para as turmas em que irá ministrar aulas, e o professor de Educação Física regente irá fazer o registro e avaliá-lo nessas aulas.

Ao final do estágio, o acadêmico organiza todas essas informações em um Relatório Final, contendo documentos entregues à escola: (os planos de atividades do acompanhamento e da regência, relatos detalhados de suas observações, os planos de aula da regência e o seu ponto de vista após o estágio). O mais importante, no final do estágio, é a reflexão do acadêmico sobre essa vivência, além do aprendizado que foi adquirido ao longo dessa etapa. Tudo o que o acadêmico vivencia na escola, sendo positivo ou negativo, contribui para sua formação profissional, faz parte da construção de sua experiência no meio escolar. Portanto, o estágio:

deveria suscitar, no professor aprendiz, o desenvolvimento da capacidade de observação, reflexão crítica e reorganização de suas ações, características que estão próximas à postura de um pesquisador/investigador, e de um autêntico professor/educador capaz de refletir e reorientar sua própria prática... gera-se uma expectativa da possibilidade de uma atividade teóricoprática que leve o futuro professor a perceber o real papel da teoria associada a uma prática, atividade desenvolvida por meio do estágio supervisionado (Lombardi, 2007, p. 120). 
Sendo assim, por meio do estágio, o discente começa a construir a sua identidade profissional, refletindo sobre o papel do professor dentro da escola e a influência de sua disciplina no contexto social. Portanto, este estudo busca verificar os conteúdos ministrados pelos acadêmicos no Estágio Supervisionado.

\section{Metodologia}

Compreendemos nossa pesquisa como quantitativa e qualitativa, classificada como documental de acordo com seus procedimentos técnicos, e exploratória quanto aos seus objetivos (Gil, 2010).

A pesquisa documental é aquela que utiliza dados já existentes de fonte documental e "vale-se de toda a sorte de documentos elaborados com finalidades diversas, tais como assentamento, autorização, comunicação, onde as fontes consultadas podem ser relatos de pesquisas, relatórios, boletins, jornais de empresas e atos jurídicos. Recomenda-se que o material consultado seja interno a uma determinada organização. Já as pesquisas exploratórias têm como propósito proporcionar maior familiaridade com o problema, com vistas a torná-lo mais explícito ou a construir hipóteses (Gil, 2010).

Nessa perspectiva, utilizamos os relatórios de estágios dos anos de 2013, 2014 e 2015 como documentos que mostram a atuação dos estagiários de Educação Física nas escolas.

Este trabalho se propôs a analisar a frequência do conteúdo nas aulas de Educação Física e também a forma em que esse conteúdo foi ministrado, a partir dos relatórios de estágio das disciplinas de Estágio Supervisionado e Prática de Ensino de Educação Física na Educação Infantil e nos anos Iniciais do Ensino Fundamental (denominado neste estudo como Estágio 1), nos anos Finais do Ensino Fundamental (denominado neste estudo como Estágio 2) e no Ensino Médio (denominado neste estudo como Estágio 3). Além disso, propomos também explorar outras variáveis que caracterizam o estágio, a fim de evidenciar possíveis reflexões sobre essa ferramenta curricular.

Foram analisados ao todo 66 relatórios, sendo 19 do estágio na Educação Infantil e nos anos Iniciais do Ensino Fundamental de 2013, 17 do estágio nos anos Finais do Ensino Fundamental de 2014 e 29 do estágio no Ensino Médio de 2015. As variáveis escolhidas para a análise dos relatórios foram: (1) número de cidades, (2) número de escolas participantes, (3) número dos anos escolares de ensino, (4) duração do estágio (em semanas), (5) atividades realizadas durante a aula, (6) conteúdos ministrados, (7) materiais utilizados, (8) local da aula, (9) referências utilizadas para o planejamento das aulas, (10) avaliação do professor supervisor dos estagiários e (11) comentários feitos na avaliação.

Em relação à variável (5) atividades realizadas durante a aula, adotou-se a categorização do tipo da atividade conforme Guedes e Guedes (1997, p. 51), em que:

a) administração/organização das atividades: situações em que os escolares recebiam instruções do professor quanto à disposição, organização e realização das atividades a serem executadas;

b) transição e/ou aguardando atividades: situações em que os escolares aguardavam o momento de participar das atividades ministradas ou em seu período de transição; 
c) prática de habilidades/destrezas motoras: atividades a mão-livre ou com materiais diversos que solicitam prioritariamente a participação de variáveis coordenativas;

d) exercícios de aptidão física: realização de exercícios físicos que podem promover o desenvolvimento e o aprimoramento dos níveis de aptidão física, categorizados em exercícios aeróbicos, de força/resistência muscular e de flexibilidade;

e) jogos de baixa organização: atividades lúdicas estruturadas na forma de conteste que solicitam o envolvimento de regras simplificadas;

f) atividades esportivas: atividades direcionadas à prática de esportes, categorizadas em fundamentação - aprendizagem, domínio e aperfeiçoamento dos gestos esportivos - e no jogo propriamente;

g) dança/expressão corporal: atividades envolvendo música que solicitam diferentes formas de expressão corporal; e

h) conceitos teóricos: apresentação de informações envolvendo conceitos associados à prática da atividade física relacionada à saúde (Guedes e Guedes, 1997, p. $51)$.

Essa categorização nos auxiliou a verificar as atividades propostas nos planos de aula. Para a análise dos dados relativos, ou seja, das variáveis que necessitaram de categorização específica, utilizou-se a técnica da análise de conteúdo descrita por Bardin (2009) como:

uma operação ou um conjunto de operações visando representar o conteúdo de um documento sob uma forma diferente do original, a fim de facilitar num estado ulterior, a sua consulta e referenciarão. Enquanto tratamento de informação contida nos documentos acumulados, a análise documental tem por objetivo dar forma conveniente e representar de outro modo essa informação, por intermédio de procedimentos de transformação (Bardin, 2009, p. 45).

Portanto, essa técnica de análise de conteúdo nos permitiu a organização para coletar as informações necessárias para a pesquisa. Dessa forma, a observação dos dados se tornou mais fácil e acessível, para interpretá-los a fim de buscar os principais objetivos do estudo.

\section{Resultados e discussão}

A Tabela 1 apresenta as variáveis sobre a realização do estágio, demonstrando o número de cidades, o número de escolas, o número de séries e a duração do estágio em semanas.

Tabela 1

Caracterização do estágio

\begin{tabular}{lcccc}
\hline & & Estágio 1 & Estágio 2 & Estágio 3 \\
\hline $\begin{array}{l}\text { Número de } \\
\text { Cidades }\end{array}$ & Total & 7 cidades & 5 cidades & 8 cidades \\
Número de & Total & 14 escolas & 14 escolas & 13 escolas
\end{tabular}




\begin{tabular}{|c|c|c|c|c|}
\hline \multirow{2}{*}{ Escolas } & Municipal & $57,1 \%$ & $64,2 \%$ & - \\
\hline & Estadual & $42,8 \%$ & $35,7 \%$ & $100 \%$ \\
\hline Número de anos & & $\begin{array}{c}1^{\circ} \text { ano }-18,6 \% \\
2^{\circ} \text { ano }-20 \% \\
3^{\circ} \text { ano }-21,3 \% \\
4^{\circ} \text { ano }-21,3 \% \\
5^{\circ} \text { ano }-18,6 \%\end{array}$ & $\begin{array}{c}6^{\circ} \text { ano }-22,4 \% \\
7^{\circ} \text { ano }-27,5 \% \\
8^{\circ} \text { ano }-25,8 \% \\
9^{\circ} \text { ano }-24,1 \%\end{array}$ & $\begin{array}{l}1^{\circ} \text { ano }-31,6 \% \\
2^{\circ} \text { ano }-36,7 \% \\
3^{\circ} \text { ano }-31,6 \%\end{array}$ \\
\hline \multirow{3}{*}{$\begin{array}{l}\text { Duração do } \\
\text { estágio }\end{array}$} & Média & 5 semanas & 5 semanas & 8 semanas \\
\hline & Mínima & 2 semanas & 2 semanas & 4 semanas \\
\hline & Máxima & 8 semanas & 10 semanas & 13 semanas \\
\hline
\end{tabular}

Nota: Fonte: Dos autores (2019)

Pode-se observar que o estágio foi realizado em sete (7) cidades no Estágio 1, cinco (5) cidades no Estágio 2 e oito (8) cidades no Estágio 3, todas do estado de Mato Grosso do Sul, totalizando 33 Instituições de Ensino e sendo a maioria Escolas Estaduais. Entre os anos que correspondem aos ciclos do Ensino Fundamental e Médio, percebeu-se que nenhum ano foi o mais requisitado para a realização das atividades de estágio, havendo um equilíbrio entre as escolhas.

Em média, a realização das regências teve duração de cinco (5) semanas para o Ensino Fundamental e oito (8) semanas para o Ensino Médio. Essa diferença é explicada em decorrência da frequência semanal das aulas, pois no Ensino Fundamental as aulas são realizadas duas vezes por semana, no Ensino Médio, uma vez por semana.

Tabela 2

Caracterização da regência do académico

\begin{tabular}{lllll}
\hline & & Estágio 1 & Estágio 2 & Estágio 3 \\
\hline \multirow{2}{*}{$\begin{array}{llll}\text { Materiais utilizados para a } \\
\text { prática }\end{array}$} & Recurso didático & $18,8 \%$ & $20 \%$ & $5 \%$ \\
& Esporte convencional & $48,9 \%$ & $64,7 \%$ & $72,6 \%$ \\
& Esporte alternativo & $15,3 \%$ & $12,3 \%$ & $15,6 \%$ \\
Locais de realização das aulas & Reaproveitável & $16,7 \%$ & $2,8 \%$ & $7,2 \%$ \\
& Quadra & $73 \%$ & $81,8 \%$ & $85,2 \%$ \\
Referência bibliográfica & Pátio & $15,3 \%$ & - & $5,8 \%$ \\
utilizada para o planejamento & Livro & $11,5 \%$ & $18,1 \%$ & $8,8 \%$ \\
das aulas & Artigo & $68,1 \%$ & $50 \%$ & $73,6 \%$ \\
& Site & $9 \%$ & - & - \\
Avaliação do professor & Não acadêmica & - & $20,8 \%$ & $10,5 \%$ \\
supervisor & Muito bom & $72,7 \%$ & $29,1 \%$ & $15,7 \%$ \\
& Bom & $28 \%$ & $94,7 \%$ & $78,5 \%$ \\
& Regular & - & $5,2 \%$ & $14,2 \%$ \\
\hline
\end{tabular}

Nota: Fonte: Dos autores (2019)

$\mathrm{Na}$ Tabela 2, estão as variáveis que caracterizam a regência do acadêmico, com informações presentes nos planos de aula e na avaliação final do supervisor, como materiais utilizados, local da aula, referências bibliográficas utilizadas para $\mathrm{o}$ planejamento das aulas e avaliação do professor supervisor sobre os estagiários. Os materiais mais utilizados na regência dos acadêmicos foram os materiais convencionais como bolas, bambolês, redes de voleibol, cordas, entre outros, apresentando uma porcentagem maior que 48,9\% em todos os estágios. No Estágio 3, os acadêmicos utilizaram também materiais alternativos, como berimbau, fita de slackline, pandeiro etc. Nos Estágios 1 e 2, optaram por utilizar mais recursos didáticos, como projetor 
multimídia, giz, mesas, som etc., e materiais reaproveitáveis, como tampinha de garrafa, papelão, garrafas, galho de árvore etc. Em relação aos materiais reaproveitáveis, a literatura indica que:

acabam apresentando vantagens aos docentes, como, os custos diminuídos, pois os recursos didáticos podem ser obtidos a partir da transformação de materiais pouco convencionais, como, por exemplo, pneus, latas, caixas de papelão, copos plásticos, etc.; as possibilidades de variação na utilização de materiais são aumentadas, contribuindo com o estímulo à motivação dos educandos; permitindo também o desenvolvimento das noções de autonomia e responsabilidade (Canestraro, Zulai e Kogut, 2008, p. 12.325).

$\mathrm{Na}$ realização da regência, a maioria das aulas foram realizadas em quadra. Esses resultados nos mostram uma característica comum da Educação Física, que possui uma frequência maior de aulas mais práticas do que teóricas. $O$ estágio que foi contemplado com mais aulas em sala de aula foi o Estágio 2, pois se acredita que nessa etapa de ensino os alunos aprendem mais sobre a história, as regras, os fundamentos, entre outros assuntos teóricos.

O tipo mais utilizado de referência bibliográfica pelos acadêmicos nos planejamentos de aula foram os livros, com mais de $50 \%$ em todos os estágios, mas ainda assim muitos utilizaram fontes não acadêmicas, como blogs, vídeos, sites e páginas de redes sociais. No geral, eles tiveram uma avaliação positiva dos professores supervisores da escola, com porcentagens de $72 \%$ a $94,7 \%$ qualificados como "muito bom".

A Tabela 3 nos mostra os principais comentários dos professores ao avaliarem os estagiários, todos esses comentários foram positivos. A maioria dos professores disse que o acadêmico "demonstrou uma boa didática durante a aula, domínio do conteúdo e as atividades foram bem desempenhadas, se mostrando um ótimo profissional". Esse comentário pode se constituir como um reflexo do que o acadêmico foi aprendendo em sua graduação. Além disso, os professores também comentaram sobre a interação do acadêmico com os alunos durante as atividades, sua responsabilidade com o estágio e as atividades inovadoras propostas, além de elogiarem os acadêmicos quanto a sua dedicação.

Tabela 3

Comentários dos professores sobre os académicos

\begin{tabular}{lc}
\hline Análise de conteúdo sobre o feedback do Professor & $\%$ \\
\hline Demonstrou uma boa didática durante a aula, domínio do conteúdo e as atividades foram & 40,9 \\
muito bem desempenhadas, se mostrando um ótimo profissional. & 26,2 \\
Interagiu muito bem com os alunos e participou durante as atividades mantendo a postura & \\
de um professor. & 14,7 \\
Mostrou-se ser uma pessoa muito prestativa, dedicada, curiosa e carismática. & 9,8 \\
Cumpriu o estágio com responsabilidade, sendo pontual com os horários e respeitando os & 8,1 \\
alunos e as normas da escola. & \\
Apresentou atividades diferentes e inovadoras, conseguindo o domínio e a concentração dos \\
alunos.
\end{tabular}

Nota: Fonte: Dos autores (2019)

A Tabela 4 representa a categorização do tipo de atividade realizada em uma aula de 50 minutos, conforme Guedes e Guedes (1997) fizeram em seu estudo. A partir dos planos de aulas e do detalhamento da aula que o acadêmico ministrou, podemos 
perceber que, nos três estágios, as atividades com maior porcentagem foram "administração/organização das atividades" e "transição e/ou aguardando as atividades". Esse resultado foi também encontrado na pesquisa de Guedes e Guedes (1997), em que os autores perceberam que os alunos passavam a maioria do tempo à espera de uma nova atividade ou ajudando em sua organização.

Tabela 4

Categorização do tipo da atividade

\begin{tabular}{llll}
\hline Atividades & Estagio 1 & Estágio 2 & Estágio 3 \\
\hline a) Administração/organização das atividades & $20,2 \%$ & $18,3 \%$ & $17,2 \%$ \\
b) Transição e/ou aguardando atividades & $20,2 \%$ & $18,3 \%$ & $17,2 \%$ \\
c) Prática de habilidades/destrezas motoras & $15,9 \%$ & $15,3 \%$ & $17,2 \%$ \\
d) Exercícios de aptidão física & $4,2 \%$ & $10,2 \%$ & $9,5 \%$ \\
e) Jogos de baixa organização & $20,2 \%$ & $17,3 \%$ & $16 \%$ \\
f) Atividades esportivas & $12,7 \%$ & $14,2 \%$ & $15 \%$ \\
g) Dança/expressão corporal & $4,2 \%$ & - & $0,5 \%$ \\
h) Conceitos teóricos & $2,12 \%$ & $26,1 \%$ & $6,5 \%$ \\
\hline
\end{tabular}

Nota: Fonte: Dos autores (2019)

Nos Estágios 1 e 3, foram desenvolvidos mais jogos de baixa organização, prática de habilidades/destrezas motoras e atividades esportivas, apresentando uma porcentagem de $12,7 \%$ a 20,2\%. No Estágio 2, percebemos que há uma frequência maior de atividades com conceitos teóricos do que de atividades mais práticas. Já as atividades menos desenvolvidas foram a dança/expressão corporal e os exercícios de aptidão física. A dança/expressão corporal foi encontrada apenas no Estágio 1, com $4,2 \%$, e no Estágio 3, com $0,5 \%$, já os exercícios de aptidão física tiveram uma frequência maior, de $4,2 \%$ a 10,2\%, aparecendo nos três estágios.

Tabela 5

Conteúdos ministrados

\begin{tabular}{llll}
\hline Conteúdos & Estágio 1 & Estágio 2 & Estágio 3 \\
\hline Anatomia: conhecimento sobre o corpo & - & $12 \%$ & $1,4 \%$ \\
Atividades recreativas & $32,3 \%$ & $4 \%$ & - \\
Atividades rítmicas e expressivas & $1,4 \%$ & - & - \\
Atletismo & $5,8 \%$ & $6 \%$ & - \\
Basquetebol & $4,4 \%$ & $14 \%$ & $12,6 \%$ \\
Capoeira & $1,4 \%$ & - & - \\
Dança & $1,4 \%$ & - & $7,4 \%$ \\
Desenvolvimento motor & $1,4 \%$ & - & - \\
Disfunção alimentar & - & - & $2 \%$ \\
Dodgeball & - & - & $2 \%$ \\
Futebol e futebol para cegos & $1,4 \%$ & - & $1,4 \%$ \\
Futsal & $16,1 \%$ & $10 \%$ & - \\
Ginástica geral & $1,4 \%$ & - & - \\
Ginástica laboral & $1,4 \%$ & - & - \\
Handebol & $2,9 \%$ & $14 \%$ & $5,6 \%$ \\
Jogos & $11,7 \%$ & $8 \%$ & $2,8 \%$ \\
Jogos de lógica & $1,4 \%$ & - & -
\end{tabular}




$\begin{array}{llll}\text { Jogos de tabuleiro } & 4,4 \% & - & - \\ \text { Natação } & 1,4 \% & - & - \\ \text { Qualidade de vida e atividade física } & - & 2 \% & 1,4 \% \\ \text { Rugby } & - & - & 4,2 \% \\ \text { Sistemas energéticos } & - & - & 2,8 \% \\ \text { Slackline } & - & 4 \% & 11,2 \% \\ \text { Voleibol } & 7,3 \% & 22 \% & 38 \%\end{array}$

Nota: Fonte: Dos autores (2019)

A Tabela 5 nos mostra todos os conteúdos ministrados pelos acadêmicos em sala de aula, foram encontrados ao todo 24 conteúdos. Aqueles que aparecem com maior frequência no Estágio 1 foram as atividades recreativas, apresentando 32,3\%, e o futsal, com 16,1\%, porém os acadêmicos utilizaram também conteúdos variados como atletismo, voleibol, capoeira, ginástica, entre outros. Nos Estágios 2 e 3, os conteúdos voleibol, handebol e basquetebol foram os mais utilizados, com porcentagens de $14 \%$ a $38 \%$. No entanto, os acadêmicos optaram também por alguns conteúdos teóricos, como anatomia, qualidade de vida e atividade física. Entre os estágios, percebemos que os esportes de quadra, como futsal, voleibol, handebol e basquetebol, foram os mais requisitados.

Pereira e Moreira (2005), ao avaliar 80 aulas para o Ensino Médio, verificaram que a participação total dos alunos foi realizada em apenas 43 aulas e que as atividades aplicadas aos alunos eram exclusivamente esportes coletivos, fundamentos técnicos para as modalidades esportivas e atividades de caráter recreativo.

Luiz et al. (1995, p. 170), fazendo reflexões sobre o estágio supervisionado na década de 1990, questionaram sobre "a necessidade de redimensionar o papel da Educação Física que ainda é visto, principalmente, como esporte ou joguinhos recreativos" (grifo nosso). Os autores evidenciaram para os educadores a necessidade de se buscar mudanças para construir junto com nossos alunos novas perspectivas, preferencialmente valorizando uma consciência crítica perante o conteúdo da Educação Física.

De acordo com Luiz et al. (1995), foi verificado que, entre os professores do $6^{\circ} \mathrm{e}$ $9^{\circ}$ ano que atuaram como supervisores de estágio, os conteúdos das aulas eram principalmente sobre habilidades básicas para a prática dos desportos como voleibol, basquetebol, futsal e handebol. Nossos dados indicaram que, passados duas décadas, esses ainda são os conteúdos mais desenvolvidos. Cabe ressaltar que os estagiários obrigatoriamente devem seguir o planejamento do professor supervisor.

As principais dificuldades para articular o trabalho dos professores de Educação Física com os alunos, conforme Luiz et al. (1995), foram o fato de as turmas serem compostas por grupos muito heterogêneos em termos de idade e de nível socioeconômico, bem como, na visão dos docentes, a maioria dos alunos preferir as aulas de Educação Física em relação às demais disciplinas, pois as consideram uma componente curricular em que podem extravasar suas energias e quebrar a monotonia da sala de aula.

Em nosso estudo, conforme Darido e Rangel (2011), percebemos uma variação de abordagens pedagógicas nos relatórios de estágio. As mais evidentes foram as abordagens desenvolvimentista, construtivista-interacionista, crítico-superadora e crítico-emancipatória. Dentre os conteúdos apresentados na Tabela 5, encontramos dois 
grupos de conteúdo, sendo eles práticos e teóricos. Os conteúdos práticos foram os mais frequentes, apresentando 82,6\%, e os conteúdos teóricos, apenas 17,4\%.

Quanto ao material utilizado no planejamento das aulas, percebemos que os acadêmicos conseguiram elaborar as aulas com materiais improvisados e convencionais. As aulas aconteceram na quadra e no pátio da escola, diferentemente de algumas pesquisas citadas neste trabalho, que apresentaram a falta de material e infraestrutura como o principal motivo para não se trabalhar com outras modalidades na escola.

É importante ressaltar também que, nos planos de aula, a maioria dos acadêmicos utilizou somente a dimensão procedimental do conteúdo, ou seja, aplicando apenas os fundamentos e as técnicas. Maldonado et al. (2014) enfatizam a necessidade de os professores utilizarem também as dimensões conceitual e atitudinal dos conteúdos. Darido e Rangel (2011, p. 66) dizem que “... na prática docente, não há como dividir os conteúdos na dimensão procedimental, atitudinal e conceitual, embora possa haver ênfases em determinadas dimensões". Englobando as três dimensões durante a aula, o conteúdo pode ser ministrado de uma forma mais completa, melhorando o ensino e a aprendizagem do aluno. Contudo, mesmo que o esporte no Ensino Médio seja o conteúdo mais ministrado em comparação com o Ensino Fundamental, existem resultados indicando que a Educação Física continua sendo a disciplina mais motivante (Chicati, 2000).

\section{Considerações finais}

Inicialmente, nosso objetivo foi verificar a realidade do estágio curricular nas aulas de Educação Física. Entretanto, na fase de análise dos relatórios, percebeu-se que os objetivos iniciais poderiam se enquadrar como um subproduto diante da riqueza dos dados obtidos e avaliados. Identificamos que o estágio supervisionado abrange várias instituições de ensino e cidades no estado de Mato Grosso do Sul, proporcionando ao acadêmico/estagiário conhecer os alunos e a realidade da escola, além de contribuir com a prática docente.

Esta vivência é muito importante para a formação de um futuro docente, pois é a partir da prática diária que o acadêmico aprende a lidar com as situações-problemas, os planejamentos de aulas, a administração do tempo e a relação entre professor e aluno, ou seja, aprende a trabalhar no ambiente escolar construindo sua identidade profissional com responsabilidade. De acordo com essa afirmação, encontramos nos relatórios de estágio que a maioria dos professores regentes, ao avaliar o acadêmico ao longo do estágio, percebeu que eles desempenharam o papel de docente com êxito, mostrando-se um excelente profissional. Além disso, percebemos que muitos acadêmicos ministraram conteúdos e atividades diferentes, utilizando materiais didáticos em sua maioria, mas também fabricaram novos materiais junto com os alunos.

Nesse estudo, foi constatado que os acadêmicos ministraram seus conteúdos utilizando conceito teórico, ludicidade, técnica e principalmente criatividade, mesmo diante da limitação de recursos encontrada nas escolas públicas para o desenvolvimento de uma Educação Física com qualidade.

Levando em consideração que os estagiários obrigatoriamente devem seguir o conteúdo que está no planejamento do professor regente da escola, percebeu-se que no Estágio 1 os acadêmicos planejaram aulas com mais jogos e brincadeiras que explorassem as habilidades básicas do ser humano. Já no Estágio 2, eles iniciaram com o ensino da teoria do esporte, 
apresentando e aprimorando as habilidades básicas por meio da técnica de cada modalidade. No Estágio 3, houve maior vivência de prática esportiva.

Considerando que o objetivo específico do estudo foi verificar a utilização dos conteúdos esporte e lazer, constatamos que as aulas trataram do conteúdo esporte, porém a falta de detalhes dos relatórios não nos possibilitou afirmar o conceito de esporte utilizado pelos acadêmicos (se rendimento ou lazer). Se considerarmos a história esportivista da Educação Física, a tendência é que essas aulas tenham sido pautadas pela técnica das modalidades. No entanto, a prática do esporte como lazer pode ter sido trabalhada, visto que esse conceito tem sido muito discutido atualmente nos cursos de formação.

Ressaltamos que a Educação Física escolar necessita se afirmar na sociedade como uma disciplina importante para o desenvolvimento de uma sociedade saudável. Assim, acreditamos que os professores precisam estar atentos para auxiliar os alunos nas relações dos conteúdos das aulas com sua utilidade prática no cotidiano fora da escola.

A limitação identificada no estudo foi principalmente em relação à falta de descrições das atividades nos planos de aula, pois os acadêmicos apresentavam o conteúdo apenas com o nome da atividade, sem especificações sobre como ela iria ser realizada. Durante a aula, o acadêmico pode passar por situações que não estão previstas, como dias chuvosos ou até mesmo uma atividade que não saia como o planejado, assim o relato seria para expor como ela foi realizada, apontando os pontos negativos e positivos, a participação dos alunos e também o resultado da aula. Acreditase que esse relato do acadêmico poderia ser mais detalhado no relatório de estágio, enriquecendo ainda mais as informações contidas nele.

\section{Referências}

Ayoub, E. (2001). Reflexões sobre a Educação Física na Educação Infantil. Revista Paulista de Educação Física, 4(15), 53-60.

Bardin, L. (2009). Análise de conteúdo. (70ª ed.). Lisboa: LDA.

Bassani, J. J., Torri, D. e Vaz, A. F. (2005). Educação do corpo, esporte e Educação Física escolar. Revista Virtual EFArtigos, (2), 24.

Bracht, V. (2005). Pesquisa (ação) e prática pedagógica em Educação Física. Coleção cotidiano escolar - A Educação Física no Ensino Fundamental (5\% $/ 8^{\circ}$ séries). Natal: Paidéia, Brasília: MEC, 7-22.

Brasil, Ministério da Educação. (2018). Base Comum Curricular Nacional. (3 Versão.).

Brasil, Ministério de Educação e do Desporto. (1998). Parâmetros Curriculares Nacionais: terceiro e quarto ciclos: Educação Física, Secretaria de Ensino Fundamental. Brasília: MEC/SEF.

Brasil, Ministério de Educação e do Desporto. (1999). Parâmetros Curriculares Nacionais: Ensino Médio/ Secretaria de Ensino Médio. Brasília: MEC/SEM.

Brasil, Presidência da República (2008). Lei $\mathrm{n}^{\circ}$ 11.788, de 25 de setembro de 2008. Dispõe sobre o estágio de estudantes. Diário Oficial da União, Brasília. Retrieved from http://www.planalto.gov.br/ccivil_03/_ato20072010/2008/lei/111788.htm. 
Canestraro, J. D. F., Zulai, L. C., e Kogut, M. C. (2008). Principais dificuldades que o professor de Educação Física enfrenta no processo ensino-aprendizagem do Ensino Fundamental e sua influência no trabalho escolar. In VIII Congresso Nacional de Educação, Curitiba.

Chemin, B. F. (2009). A educação para e pelo lazer no âmbito municipal. Educação, 32(2), 165-175.

Chicati, K. C. (2000) Motivação nas aulas de educação física no ensino médio. Revista da Educação Física, Maringá, 11(1), 97-105.

Darido, S. C., e Rangel, I. C. A. (2011). Educação Física na escola: implicações para a prática pedagógica. Grupo Gen-Guanabara Koogan. (2a ed.). Rio de Janeiro: Grupo Gen-Guanabara Koogan. (Obra original publicada em 2000).

Darido, S. C., Galvão, Z., Ferreira, L. A., e Fiorin, G. (1999). Educação Física no Ensino Médio: reflexões e ações. Motriz, 5(2), 138-145.

Frometa, E. R., e Takahashi, K. (2004). Guia Metodológico em atletismo: formação técnica e treinamento. Porto Alegre: Artmed.

Gil, A. C. (2010). Como elaborar projetos de pesquisa. (5ª ed.). São Paulo: Atlas.

Guedes, D. P., e Guedes, J. E. R. (1997). Características dos programas de Educação Física Escolar. Revista Paulista de Educação Física, 11, 49-62.

Hildebrandt, R., e Laging, R. (2003). Concepções abertas no ensino da Educação Física. Rio de Janeiro: Ao Livro Técnico.

Lombardi, R. F. (2007). Estágio supervisionado: importante na e para a formação do professor. In D. R. T. G. Carvalho, S. S. Utari. Formação de Professores e estágios supervisionados: algumas veredas, (pp.11-126). São Paulo: Andross.

Luiz, F. R., Angeloni, S., De Maria, L. J., Maltez, M. F. e Batinga, O. A. (1995). Desvendando o estágio em Educação Física. Revista Motrivivência, 5, 170-176.

Maldonado, D. T., Bocchini, D., Barreto, A., e Rodrigues, G. M. (2014). As dimensões atitudinais e conceituais dos conteúdos na educação física escolar. Pensar a Prática, 17(2).

Manual de orientação do Estágio Supervisionado: Licenciatura em Educação Física. (2016). Faculdade de Educação, Dourados: UFDG

Matthiensen, S. Q. (2007). Atletismo: teoria e prática. Rio Janeiro: Guanabara Koogan.

Matthiesen, S. Q., Calvo, A. P., Silva, A. C., e Faganello, F. R. (2005). Atletismo se aprende na escola. Revista Motricidade, 1(1), 36-47.

Netto, R. S., e Pimentel, G. G. A. (2009). O ensino do atletismo nas aulas de educação física. Curitiba: SEED/PR.

Oliveira, M. C. M. (2006). Atletismo escolar: uma proposta de ensino na educação infantil. Rio de Janeiro: Sprint.

Pereira, R. S., e Moreira, E. C. (2005). A participação dos alunos do ensino médio em aulas de Educação Física: algumas considerações. Journal of Physical Education, 16(2), 121-127. 
Silva Marques, C. L. e Iora, J. A. (2009). Atletismo Escolar: possibilidades e estratégias de objetivo, conteúdo e método em aulas de Educação Física. Movimento, 15(2), 113-118.

Silva, R. R. e Soares, M. G. (2011). Atletismo escolar: concepção dos professores sobre a natureza do atletismo e possibilidade de ensino. Pará: UEPA.

Souza, E. R. (2005). O atletismo no Ensino Fundamental: reflexões teóricas e possibilidades pedagógicas. Florianópolis - SC, UFSC: Edição do Autor.

UFGD. (2016). Manual de orientação do Estágio Supervisionado: Licenciatura em Educação Física. Faculdade de Educação. Dourados-MS.

Data de recepção: $25 / 05 / 2019$

Data de revisão: 07/06/2019

Data do aceite: 27/06/2019 
